\title{
Biodistribution and Radiation Dosimetry for the Chemokine Receptor CXCR4-Targeting Probe ${ }^{68}$ Ga-Pentixafor
}

\author{
Ken Herrmann*1,2, Constantin Lapa*1, Hans-Juergen Wester ${ }^{3,4}$, Margret Schottelius ${ }^{3}$, Christiaan Schiepers ${ }^{2}$, \\ Uta Eberlein $^{1}$, Christina Bluemel ${ }^{1}$, Ulrich Keller ${ }^{5}$, Stefan Knop ${ }^{6}$, Saskia Kropf ${ }^{4}$, Andreas Schirbel ${ }^{1}$, Andreas K. Buck ${ }^{1}$, \\ and Michael Lassmann ${ }^{1}$ \\ ${ }^{1}$ Department of Nuclear Medicine, University Hospital Würzburg, Würzburg, Germany; ${ }^{2}$ Department of Molecular and Medical \\ Pharmacology, David Geffen School of Medicine at UCLA, Los Angeles, California; ${ }^{3}$ Pharmaceutical Radiochemistry, Technische \\ Universität München, Munich, Germany; ${ }^{4}$ Scintomics GmbH, Fürstenfeldbruck, Germany; ${ }^{5}$ III. Medical Department of Hematology \\ and Medical Oncology, Technische Universität München, Munich, Germany; and ${ }^{6}$ Division of Hematology and Medical Oncology, \\ Department of Internal Medicine II, Universitätsklinikum Würzburg, Würzburg, Germany
}

\begin{abstract}
${ }^{68}$ Ga-pentixafor is a promising PET tracer for imaging the expression of the human chemokine receptor 4 (CXCR4) in vivo. The whole-body distribution and radiation dosimetry of ${ }^{68} \mathrm{Ga}$-pentixafor were evaluated. Methods: Five multiple-myeloma patients were injected intravenously with $90-158 \mathrm{MBq}$ of ${ }^{68} \mathrm{Ga}$-pentixafor (mean \pm $\mathrm{SD}, 134 \pm 25 \mathrm{MBq}$ ), and a series of 3 rapid multiple-bed-position whole-body scans were acquired immediately afterward. Subsequently, 4 static whole-body scans followed at $30 \mathrm{~min}, 1 \mathrm{~h}, 2 \mathrm{~h}$, and $4 \mathrm{~h}$ after administration of the radiopharmaceutical. Venous blood samples were obtained. Time-integrated activity coefficients were determined from multiexponential regression of organ region-of-interest data normalized to the administered activity, for example, the time-dependent percentages of the injected activity per organ. Mean organ-absorbed doses and effective doses were calculated using OLINDA/EXM. Results: The effective dose based on $150 \mathrm{MBq}$ of ${ }^{68} \mathrm{Ga}$-pentixafor was $2.3 \mathrm{mSv}$. The highest organabsorbed doses (for $150 \mathrm{MBq}$ injected) were found in the urinary bladder wall (12.2 mGy), spleen (8.1 mGy), kidneys (5.3 mGy), and heart wall (4.0 mGy). Other organ mean absorbed doses were as follows: $2.7 \mathrm{mGy}$, liver; $2.1 \mathrm{mGy}$, red marrow; $1.7 \mathrm{mGy}$, testes; and 1.9 mGy, ovaries. Conclusion: ${ }^{68} \mathrm{Ga}$-pentixafor exhibits a favorable dosimetry, delivering absorbed doses to organs that are lower than those delivered by ${ }^{18} \mathrm{~F}-\mathrm{FDG}-$ or ${ }^{68} \mathrm{Ga}-$ labeled somatostatin receptor ligands.
\end{abstract}

Key Words: PET; CXCR4; ${ }^{68} \mathrm{Ga}$; dosimetry

J Nucl Med 2015; 56:410-416

DOI: 10.2967/jnumed.114.151647

\section{$\mathbf{I}$} providing predictive biomarkers for patient stratification toward the best therapy. In this context, the successful targeting of somatostatin receptors in neuroendocrine tumors can serve as a paradigm for the feasibility and efficacy of theranostic systems (1).

\footnotetext{
Received Nov. 12, 2014; revision accepted Jan. 9, 2015.

For correspondence or reprints contact: Ken Herrmann, Department of Nuclear Medicine, University Hospital Würzburg, Oberdürrbacher Strasse 6, 97080 Würzburg, Germany.

E-mail: Herrmann_K1@ukw.de

${ }^{*}$ Contributed equally to this work.

Published online Feb. 19, 2015.

COPYRIGHT (C 2015 by the Society of Nuclear Medicine and Molecular Imaging, Inc.
}

The interaction of hematologic and solid tumor cells with their microenvironment by chemokine receptors and their corresponding ligands represents an important target for anticancer treatment. This mechanism protects malignant cells from genotoxic stresses such as chemotherapy (2). An important representative of these chemokine receptor-ligand pairs is the chemokine receptor 4 (CXCR4) and its ligand CXCL12. The receptor plays an important role in a variety of physiologic processes that rely on the recruitment and homing of stem cells, progenitor cells, and immune cells. It is thus important in embryogenesis, neoangiogenesis, hematopoiesis, and inflammation. CXCR4 is overexpressed in more than 20 human tumor types including ovarian, prostate, esophageal, and renal cell carcinoma, promoting tumor growth and progression, tumor invasiveness, and metastasis (2). CXCR4 was, therefore, identified as an important target for cancer diagnosis and therapy (3).

Recently, Wester et al. developed ${ }^{68} \mathrm{Ga}$-pentixafor $\left({ }^{68} \mathrm{Ga}-\mathrm{CPCR} 4.2\right)$, a cyclic pentapeptide that enables sensitive and high-contrast imaging of human CXCR4 expression in vivo $(4,5)$. In addition, ligands for CXCR4-targeted radionuclide therapy, developed by the same group and suitable for radiolabeling with therapeutic $\beta$ emitters such as ${ }^{90} \mathrm{Y}$ or ${ }^{177} \mathrm{Lu}$ or $\alpha$ emitters such as ${ }^{213} \mathrm{Bi}$ or ${ }^{225} \mathrm{Ac}$, are currently under evaluation for therapy of advanced small cell lung cancer and multiple myeloma. As with any new radiopharmaceutical, the whole-body distribution (e.g., the time-dependent percentage of the injected activity per organ) and normal-organ radiation dosimetry (e.g., mean absorbed dose) of ${ }^{68}$ Ga-pentixafor must be determined before its clinical translation. The aim of this article was to quantify the biokinetics and the dosimetry of ${ }^{68} \mathrm{Ga}-$ pentixafor in multiple-myeloma patients.

\section{MATERIALS AND METHODS}

\section{Subjects and Research Design}

Five patients (4 men, 1 woman; age, 50-72 y; mean age \pm SD, $62 \pm$ 9 y) with a history of multiple myeloma were scanned. All patients experienced long-standing, progressive disease (median duration, 28 mo; range, 12-117 mo) and had been treated with various chemotherapies, including novel agents such as bortezomib, lenalidomide, and others. Four of the 5 patients had undergone autologous stem cell transplantation.

PET scans were obtained to measure the expression of CXCR4 as a potential therapeutic target for a $\beta$-emitter-linked receptor ligand. Detailed patient characteristics are given in Table $1 .{ }^{68} \mathrm{Ga}$-pentixafor was administered in compliance with The German Medicinal Products Act, AMG $\S 132 \mathrm{~b}$, and in accordance with the responsible regulatory 
TABLE 1

Patients' Demographic Data

\begin{tabular}{|c|c|c|c|c|c|c|c|c|}
\hline Patient & Sex & Age $(y)$ & Height (cm) & Weight (kg) & Activity (MBq) & Myeloma type & Disease duration (mo) & Previous therapies \\
\hline P1 & M & 72 & 178 & 93 & 156 & $\lg G \mathrm{~K}$ & 12 & CTx \\
\hline $\mathrm{P} 2$ & $\mathrm{~F}$ & 64 & 164 & 84 & 90 & $\lg G \mathrm{~K}$ & 117 & CTx, Auto-Tx \\
\hline P3 & M & 56 & 180 & 90 & 141 & $\lg A \mathrm{~K}$ & 28 & CTx, Auto-Tx \\
\hline P4 & M & 50 & 168 & 63 & 158 & $\operatorname{LC} \lambda$ & 38 & CTx, Auto-Tx \\
\hline P5 & M & 69 & 176 & 81 & 125 & $\lg G \lambda$ & 26 & CTx, Auto-Tx \\
\hline
\end{tabular}

$\mathrm{K}=$ type of light chain; CTx = chemotherapy; Auto-Tx = autologous stem cell transplantation; LC = light chains; $\lambda=$ type of light chain.

body (Regierung von Unterfranken) (6). The data analysis was disclosed to the ethics committee of the Universitätsklinikum Würzburg, and the need of a formal review was waived.

Safety was assessed by monitoring adverse events; clinical laboratory tests included total blood count, renal and hepatic function tests, and vital signs (heart rate, blood pressure) up to $14 \mathrm{~d}$ after administration of ${ }^{68} \mathrm{Ga}$-pentixafor.

\section{Preparation of CXCR4-Targeting Probe ${ }^{68} \mathrm{Ga}-P e n t i x a f o r$}

${ }^{68} \mathrm{Ga}$-pentixafor was synthesized in a fully automated, good manufacturing practice-compliant procedure using a GRP module (SCINTOMICS $\mathrm{GmbH}$ ) connected to a ${ }^{68} \mathrm{Ge} /{ }^{68} \mathrm{Ga}$ generator (Cyclotron Co. Ltd.) and equipped with a disposable single-use cassette kit (ABX), using the standardized labeling sequence previously described (6) and $40 \mu \mathrm{g}$ of unlabeled ${ }^{68} \mathrm{Ga}$-pentixafor (SCINTOMICS GmbH) (Supplemental Fig. 1; supplemental materials are available at http://jnm.snmjournals.org). monographs 2462 (Gallium Chloride) and 2482 (Gallium Edotreotide) of the European Pharmacopoeia by analytic high-performance liquid chromatography. Analytic high-performance liquid chromatography was performed on a SCINTOMICS system equipped with a RP-18 column (Nucleosil, $125 \times 4.6 \mathrm{~mm}$; CS-Chromatographie). The eluent was a linear gradient from $100 \%$ water $(0.1 \%$ trifluoroacetic acid) to $100 \% \mathrm{MeCN}$ (0.1\% trifluoroacetic acid) over $20 \mathrm{~min}$. Additionally, the radiochemical purity of the tracer was determined with a miniGITA TLC-scanner (Raytest) using Varian silica gel-impregnated glass fiber sheets and $0.1 \mathrm{M}$ sodium citrate as eluent.

\section{PET Imaging}

All ${ }^{68}$ Ga-pentixafor scans were obtained on a dedicated (PET/CT) scanner (Biograph mCT 64; Siemens Medical Solutions) after patients Before use, the radiopharmaceuticals were analyzed according to the

fasted for $4 \mathrm{~h}$. Injected activity ranged from 90 to $158 \mathrm{MBq}$ (mean, $134 \pm 25 \mathrm{MBq})$. Activity remaining in the injection syringe was quantified and considered.

Low-dose CT scans for attenuation correction were acquired ( $35 \mathrm{mAs}, 120 \mathrm{keV}$, a $512 \times 512$ matrix, 5 -mm slice thickness with a total of 201 slices, increment of $30 \mathrm{~mm} / \mathrm{s}$, rotation time of $0.5 \mathrm{~s}$, and pitch of 0.8 ). The imaging field ranged from the base of the skull to the proximal thighs. Immediately after injection, the PET imaging sequence started with a series of 3 rapid multiple-bed-position whole-body scans $300 \mathrm{~s}$ each. Subsequently, 4 static whole-body scans encompassing 6-7 bed positions were acquired at $30 \mathrm{~min}, 1 \mathrm{~h}, 2 \mathrm{~h}$, and $4 \mathrm{~h}$ after administration of the radiopharmaceutical. The total image acquisition time was approximately $109 \mathrm{~min}$. All data were decay-corrected to the starting time of the individual scan $(0.1,5,10,30,60,120$, and $240 \mathrm{~min})$, which varied slightly from subject to subject because of different amounts of bed positions acquired per frame. The first 2 subjects were scanned starting at mid thigh, which was changed to head first for the last 3 subjects to be able to obtain the peak of the uptake for the upper organs.

All PET images were reconstructed using corrections for attenuation, dead-time, random events, and scatter. The PET scanner is periodically checked for calibration accuracy as part of quality control according to published guidelines (7).

\section{Blood Sampling and Activity Determination of Blood Samples}

Blood samples were drawn in all patients before administration and at 2, 5, 10, 20, and $30 \mathrm{~min}$ and at 1, 2, and $4 \mathrm{~h}$ after administration. For an exact quantification of the blood activity concentration, an aliquot of $1 \mathrm{~mL}$ of each heparinized blood sample was measured in a well counter. The counting efficiency of the detector was determined by repeated measurements of a National Institute of Standards and Technology-traceable standard. The values were decay-corrected to the time of blood drawing.
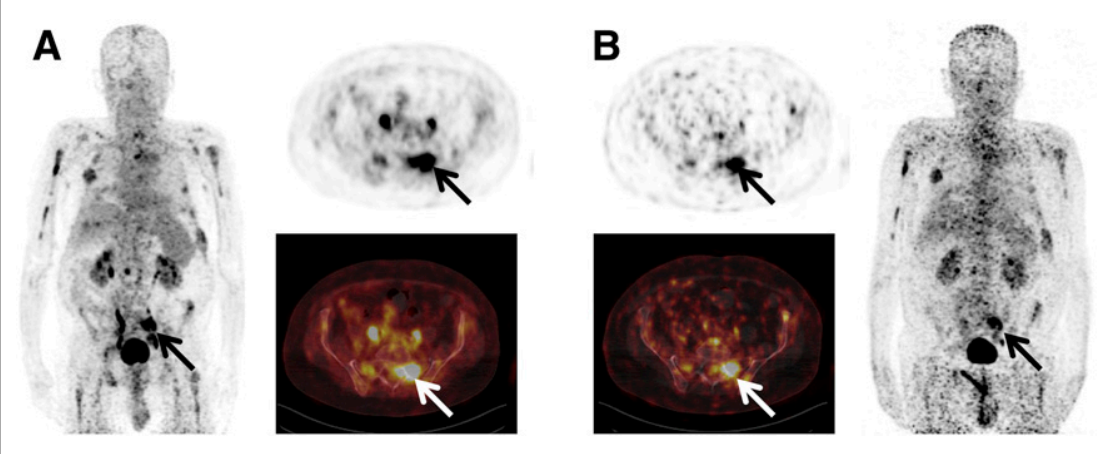

FIGURE 1. Example of high tumor-to-background ratios in multiple-myeloma patient (patient 5). Shown are maximum-intensity projections (A, left; $B$, right) as well as transaxial slices (A, right; $B$, left) at 40 (A) and 236 (B) min after injection of ${ }^{68} \mathrm{Ga}$-pentixafor. Numerous myeloma lesions (biggest lesion in left os sacrum highlighted) can be depicted up to $4 \mathrm{~h}$ after injection.

\section{Imaging and Dosimetry}

The dosimetry was performed according to recommendations for good dosimetry reporting of the European Association of Nuclear Medicine (8). Full organ segmentation was performed by a single observer on CT images and PET images for clearly visible organs (e.g., gallbladder, heart, kidneys, spleen, liver, and bladder), the whole body, and lesions using E.SOFT software VA60C (Siemens Medical Solutions). For bone marrow dosimetry, CTbased volumes of interest were drawn for lumbar vertebrae L2-L4. From the coregistered PET images, we obtained average organ activity per volume in $\mathrm{kBq} / \mathrm{mL}$ for each frame 


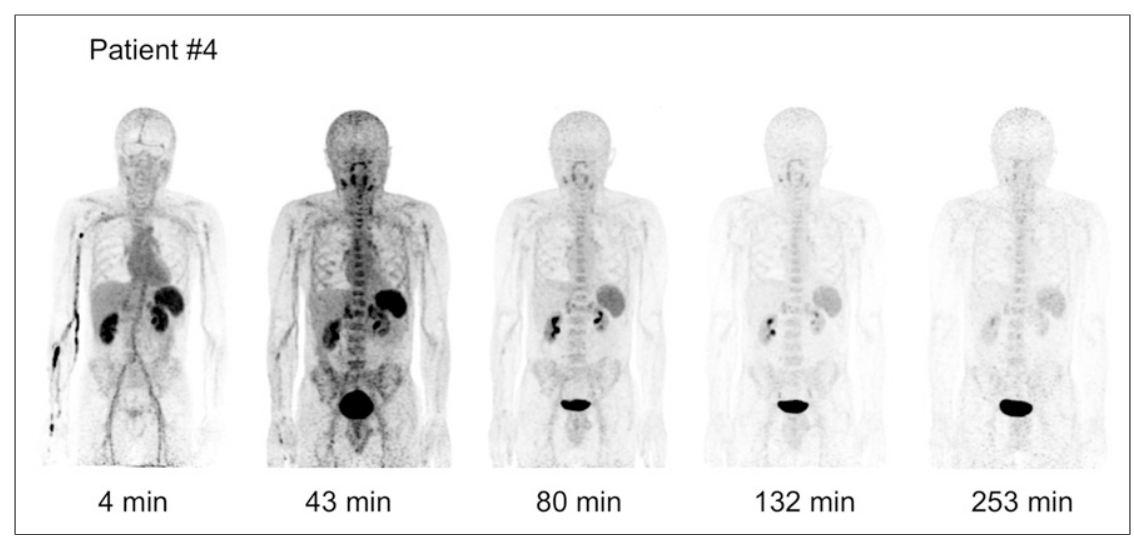

FIGURE 2. Sequential patient scan.

and, subsequently, the total activity in the respective volume of interest. Because the scanning was done from the base of the skull to mid thigh, all measured activities were normalized to the injected activity for each patient to calculate relative time-activity curves.

In addition, representative lesions (the largest lesion per subject) were segmented for an analysis of the optimal scanning time after administration.

Time-activity curves were integrated using the software NUKFIT (9). This software selects a set of fitting functions from predefined sums of exponentials and the choice of an error model for the data used. Visual inspection, the coefficient of determination, the SE of the fitted parameters, and the correlation matrix are provided to characterize the quality of the respective fits. The functions that are best supported by the data are determined using the corrected Akaike information criterion (9). The time-integrated activity coefficient is estimated by analytically integrating the fitted functions. Its SE is determined assuming gaussian error propagation. For this investigation, a systematic error in activity quantification of $10 \%$ was assumed. The time-activity curves of the urinary bladder contents were integrated using a trapezoidal integration and assuming physical decay after the last data point.

The time-integrated activity coefficient for the bone marrow was calculated using 2 methods proposed by Ferrer et al. for radioimmunotherapy (10) to check for differences in bone marrow timeintegrated activity coefficients when applying different methods. The first method is blood-based. The underlying assumptions are that there

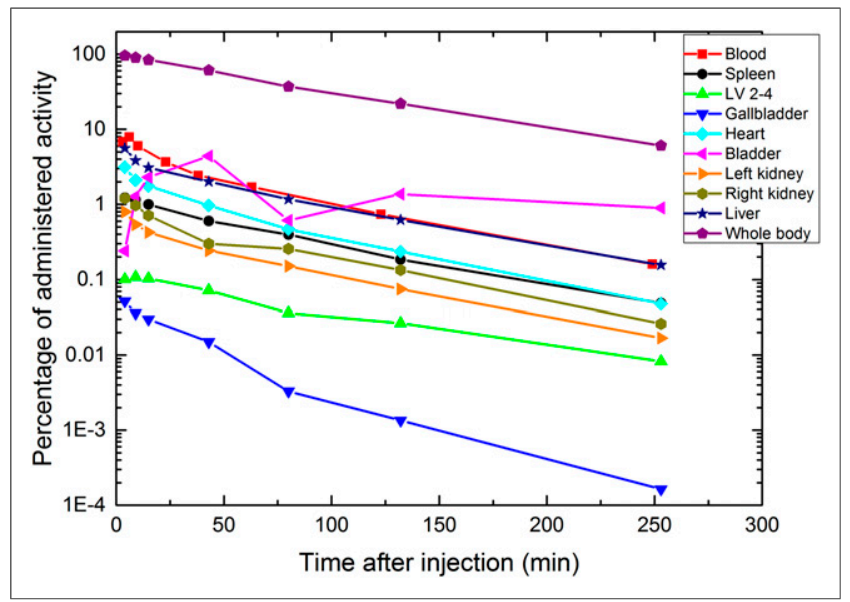

FIGURE 3. Time-activity curves for patient 4 for all organs showing uptake, for whole body, and for blood. For blood, percentage of activity is given per liter of blood. LV 2-4 = lumbar vertebrae L2-L4. is no specific radiopharmaceutical binding in blood or red marrow and the activity concentration in the bone marrow is proportional to that in blood. If there is no specific radiopharmaceutical binding in blood or red marrow, the time-integrated activity concentration in blood $C_{\text {blood }}$ can be used to assess the timeintegrated activity concentration in red marrow $\tilde{A}_{R M}$ using the red marrow-to-blood activity concentration ratio (RMBLR),

$$
\tilde{A}_{R M}=R M B L R \times C_{\text {blood }} \times m_{R M}, \quad \text { Eq. } 1
$$

where $\mathrm{m}_{\mathrm{RM}}$ is equal to $1,500 \mathrm{~g}(10)$. According to Sgouros (11), RMBLR depends on the hematocrit and is equal to $0.19 /(1-$ hematocrit $)$, leading to an RMBLR of 0.36 for a normal value of hematocrit. In this investigation, we set RMBLR to a constant value of 0.36 , neglecting patient-specific variations.

The second method uses the time-integrated activities $\tilde{A}_{L 2-L 4}$ of the lumbar vertebrae L2-L4 for assessing activity in the red bone marrow, assuming that $6.7 \%$ of the total bone marrow is contained in L2-L4 (10):

$$
\tilde{A}_{R M}=\frac{\tilde{A}_{L 2-L 4}}{0.067}
$$

Because Ferrer et al. (10) showed that the second method obtained results that compared better with clinical findings, the absorbed dose to the bone marrow was calculated using the time-integrated activity coefficients of the image-based method.

The individual time-integrated activity coefficients were used for calculating effective doses for the standard $70-\mathrm{kg}$ adult male model with OLINDA/EXM (12) for each patient separately. Entering the mean values of the time-integrated activity coefficients into OLINDA/EXM provided organ-absorbed doses and effective doses (based on tissue-weighting factors from publication 60 of the International Commission on Radiological Protection [ICRP] (13)) for a standard patient. SDs were calculated using Excel (Microsoft).

In addition, the effective dose applied according to ICRP 103 (14) was calculated despite the fact that the organ-absorbed dose rates per unit activity values for radiopharmaceuticals based on the latest ICRP voxel phantoms in ICRP 110 (15) have not yet been published (16). Because there was only 1 female patient, a sex-specific calculation was not been performed.

\section{RESULTS}

\section{Radioligand}

The administered amount of ${ }^{68} \mathrm{Ga}$-pentixafor was less than 20 $\mu \mathrm{g}$. The overall activity (radiochemical purity $>98 \%$ ) injected per patient was 90-158 MBq (mean, $134 \pm 25 \mathrm{MBq}$ ), with a specific activity greater than $5 \mathrm{MBq} / \mu \mathrm{g}$.

\section{Patients}

Injection of ${ }^{68} \mathrm{Ga}$-pentixafor was well tolerated by all subjects. No side effects were observed during or after the study. No clinically significant laboratory changes or changes in vital signs were identified.

On visual image analysis of the scans, 2 of the 5 patients (patients 2 and 5) presented focal ${ }^{68} \mathrm{Ga}$-pentixafor-positive lesions (Fig. 1). All lesions were confined to the bone marrow; no extramedullary disease was revealed. In the other subjects, only heterogeneous tracer uptake of the skeleton was recorded. 


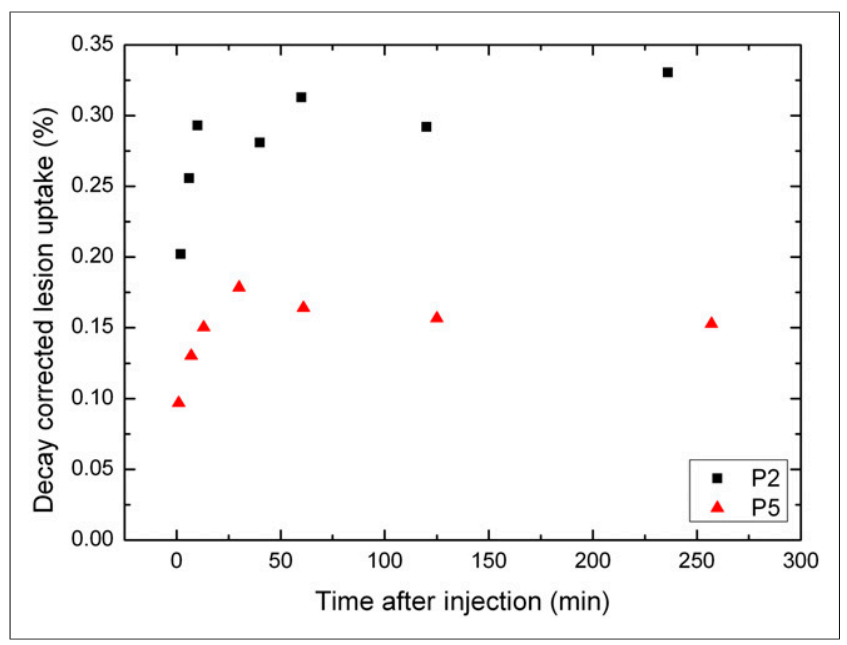

FIGURE 4. Decay-corrected uptake as percentage of administered activity for 2 visible lesions in patients 2 and 5 (P2 and P5, respectively).

\section{Image Analysis}

The biodistribution of ${ }^{68} \mathrm{Ga}$-pentixafor over time was determined for major organs in 5 patients. Figure 2 illustrates whole-body maximum-intensity projections of a representative subject (patient 4) at different time points after administration of ${ }^{68} \mathrm{Ga}$-pentixafor. Scans were obtained at all nominal time points in all patients; 8 blood samples were collected in all patients but patient 3. In this patient, only 5 samples were taken.

Figure 3 shows the time-activity curves for various organs and the blood (per liter of blood) in percentage of the injected activity for the same patient as in Figure 2 (patient 4). The highest uptake was observed in the liver, with an initial value of $5.6 \%$ of injected activity after $4 \mathrm{~min}$, followed by a rapid washout phase to $0.2 \%$ after $4 \mathrm{~h}$. Significant tracer uptake was also observed in the heart with $3.1 \%$ after $4 \mathrm{~min}$, declining to less than $0.1 \%$ after $4 \mathrm{~h}$. The gallbladder was characterized by a low uptake, compared with other visible organs. Similar time-activity curves were seen in all other patients. The highest uptake in the bladder contents before first voiding $(5.7 \%)$ was observed in patient 3 . All other patients showed uptake of less than $5 \%$ of the injected activity. All patients voided for the first time 40-60 min after administration of the radioligand. Lesion analysis could be performed only in patients 2 and 5. The time course of the decay-corrected uptake is summarized in Figure 4 (lesion size patient 2, $15.8 \mathrm{~mL}$; lesion size patient 5, $23.7 \mathrm{~mL}$ ). The other patients showed no detectable lesion uptake.

In patient 5, the maximum lesion uptake after tracer administration was observed after $30 \mathrm{~min}$ whereas in patient 2 the values varied between $0.29 \%$ and $0.33 \%$ after $10 \mathrm{~min}$ and thus showed no appreciable washout. The variability observed at late time points in patient 2 is most likely caused by the difficulties we had in determining the lesion volume for this specific lesion by PET or CT. The target-to-background ratios (background volume of interest, remainder of the body) were highest after $30 \mathrm{~min}$, indicating that this is the optimal time point for scanning. The scans at different time points were also inspected visually by 2 experienced observers for determining the optimal time span for scanning, which is between 30 and $60 \mathrm{~min}$.

\section{Dosimetry}

Time-integrated activity coefficients of segmented organs were calculated and are shown in Table 2 for each patient individually. In addition, the mean values for all patients are given. All corresponding errors for calculating the individual time-activity curves were less than $5 \%$, with the exception of the curve for the right kidney of patient $1(12 \%)$. These results are not shown in Table 1 as they were much smaller as compared with the SD when comparing all patients (Table 1) and were, therefore, neglected for the calculation of the mean absorbed doses to the organs.

The highest number of disintegrations per organ occurred in the bladder contents, with an average time-integrated activity coefficient of $0.06 \mathrm{~h}$, followed by the liver $(0.05 \mathrm{~h})$. The relative contribution of the number of disintegrations in the bladder

TABLE 2

Time-Integrated Activity Coefficients (h)

\begin{tabular}{|c|c|c|c|c|c|c|c|}
\hline \multirow[b]{2}{*}{ Source organ } & \multicolumn{5}{|c|}{ Patient } & \multirow[b]{2}{*}{ Mean } & \multirow[b]{2}{*}{$\mathrm{SD}$} \\
\hline & $\mathrm{P} 1$ & $\mathrm{P} 2$ & P3 & $\mathrm{P} 4$ & $\mathrm{P} 5$ & & \\
\hline Remainder & 1.409 & 1.164 & 1.092 & 1.256 & 1.209 & 1.226 & 0.119 \\
\hline Liver & 0.074 & 0.053 & 0.054 & 0.048 & 0.043 & 0.054 & 0.012 \\
\hline Right kidney & 0.014 & 0.010 & 0.010 & 0.009 & 0.008 & 0.010 & 0.002 \\
\hline Left kidney & 0.015 & 0.009 & 0.012 & 0.006 & 0.008 & 0.010 & 0.003 \\
\hline Kidneys (sum) & 0.029 & 0.019 & 0.022 & 0.016 & 0.016 & 0.020 & 0.005 \\
\hline Heart & 0.042 & 0.031 & 0.025 & 0.022 & 0.022 & 0.029 & 0.009 \\
\hline Bladder contents & 0.021 & 0.058 & 0.085 & 0.080 & 0.063 & 0.061 & 0.025 \\
\hline Gallbladder & - & 0.0004 & 0.0006 & 0.0003 & 0.0010 & 0.0006 & 0.0004 \\
\hline Spleen & 0.024 & 0.026 & 0.017 & 0.015 & 0.018 & 0.020 & 0.005 \\
\hline LV2-4 & 0.002 & 0.003 & 0.001 & 0.002 & 0.001 & 0.002 & 0.001 \\
\hline Red marrow LV & 0.032 & 0.048 & 0.015 & 0.025 & 0.022 & 0.028 & 0.012 \\
\hline Red marrow blood & 0.022 & 0.031 & 0.024 & 0.032 & 0.012 & 0.024 & 0.008 \\
\hline
\end{tabular}

LV2-4 = lumbar vertebrae L2-L4.

Red marrow LV and red marrow blood: for calculation methods, see "Materials and Methods" section. 
TABLE 3

Absorbed Organ Dose Coefficients and Absorbed Organ Doses (150 MBq of ${ }^{68}$ Ga-Pentixafor)

\begin{tabular}{|c|c|c|c|c|}
\hline Target organ & $\beta$ (mGy/MBq) & Photon (mGy/MBq) & Total (mGy/MBq) & $\begin{array}{c}\text { Absorbed dose (mGy) } \\
(150 \mathrm{MBq})\end{array}$ \\
\hline Adrenals & $7.10 \mathrm{E}-03$ & $5.18 \mathrm{E}-03$ & $1.23 \mathrm{E}-02$ & 1.85 \\
\hline Brain & $7.10 \mathrm{E}-03$ & $2.93 \mathrm{E}-03$ & $1.00 \mathrm{E}-02$ & 1.50 \\
\hline Breasts & $7.10 \mathrm{E}-03$ & $2.78 \mathrm{E}-03$ & $9.88 \mathrm{E}-03$ & 1.48 \\
\hline Gallbladder wall & $9.27 \mathrm{E}-03$ & $5.30 \mathrm{E}-03$ & $1.46 \mathrm{E}-02$ & 2.19 \\
\hline Lower large intestine wall & $7.10 \mathrm{E}-03$ & $5.38 \mathrm{E}-03$ & $1.25 \mathrm{E}-02$ & 1.88 \\
\hline Small intestine & $7.10 \mathrm{E}-03$ & $5.18 \mathrm{E}-03$ & $1.23 \mathrm{E}-02$ & 1.85 \\
\hline Stomach wall & $7.10 \mathrm{E}-03$ & $4.84 \mathrm{E}-03$ & $1.19 \mathrm{E}-02$ & 1.79 \\
\hline Upper large intestine wall & $7.10 \mathrm{E}-03$ & $5.00 \mathrm{E}-03$ & $1.21 \mathrm{E}-02$ & 1.82 \\
\hline Heart wall & $2.06 \mathrm{E}-02$ & $5.88 \mathrm{E}-03$ & $2.65 \mathrm{E}-02$ & 3.98 \\
\hline Kidneys & $2.84 \mathrm{E}-02$ & $6.61 \mathrm{E}-03$ & $3.50 \mathrm{E}-02$ & 5.25 \\
\hline Liver & $1.22 \mathrm{E}-02$ & $5.30 \mathrm{E}-03$ & $1.75 \mathrm{E}-02$ & 2.68 \\
\hline Lungs & $7.10 \mathrm{E}-03$ & $3.91 \mathrm{E}-03$ & $1.10 \mathrm{E}-02$ & 1.65 \\
\hline Muscle & $7.10 \mathrm{E}-03$ & $3.78 \mathrm{E}-03$ & 1.09E-02 & 1.64 \\
\hline Ovaries & $7.10 \mathrm{E}-03$ & $5.54 \mathrm{E}-03$ & $1.26 \mathrm{E}-02$ & 1.89 \\
\hline Pancreas & $7.10 \mathrm{E}-03$ & $5.74 \mathrm{E}-03$ & $1.28 \mathrm{E}-02$ & 1.92 \\
\hline Red marrow & $9.72 \mathrm{E}-03$ & 4.27E-03 & $1.40 \mathrm{E}-02$ & 2.10 \\
\hline Osteogenic cells & $1.40 \mathrm{E}-02$ & 4.36E-03 & $1.84 \mathrm{E}-02$ & 2.76 \\
\hline Skin & $7.10 \mathrm{E}-03$ & $2.43 E-03$ & $9.53 \mathrm{E}-03$ & 1.43 \\
\hline Spleen & 4.53E-02 & $8.50 \mathrm{E}-03$ & $5.38 \mathrm{E}-02$ & 8.07 \\
\hline Testes & $7.10 \mathrm{E}-03$ & $3.92 \mathrm{E}-03$ & $1.10 \mathrm{E}-02$ & 1.65 \\
\hline Thymus & $7.10 \mathrm{E}-03$ & 4.19E-03 & $1.13 \mathrm{E}-02$ & 1.70 \\
\hline Thyroid & $7.10 \mathrm{E}-03$ & $3.74 \mathrm{E}-03$ & $1.08 \mathrm{E}-02$ & 1.62 \\
\hline Urinary bladder wall & $6.91 \mathrm{E}-02$ & $1.23 \mathrm{E}-02$ & $8.14 \mathrm{E}-02$ & 12.21 \\
\hline Uterus & $7.10 \mathrm{E}-03$ & $6.53 \mathrm{E}-03$ & $1.36 \mathrm{E}-02$ & 2.04 \\
\hline Total body & $7.91 \mathrm{E}-03$ & $3.80 \mathrm{E}-03$ & 1.17E-02 & 1.76 \\
\hline $\begin{array}{l}\text { Effective dose } \\
\text { coefficient (mSv/MBq) }\end{array}$ & & & $1.56 \mathrm{E}-02$ & \\
\hline $\begin{array}{l}\text { Effective dose coefficient } \\
\quad(\mathrm{mSv} / \mathrm{MBq})^{\star}\end{array}$ & & & $1.58 \mathrm{E}-02 \pm 0.06 \mathrm{E}-02$ & \\
\hline Effective dose (mSv) & & & & 2.34 \\
\hline
\end{tabular}

contents to the total number of disintegrations in the whole body was $4 \%$. The average absorbed dose/dose coefficients across all subjects are shown in Table $3( \pm \mathrm{SD})$. The highest absorbed dose per unit activity was observed in the urinary bladder wall (8.14E-02 mGy/MBq), followed by the spleen (5.38E-02 mGy/MBq) and the kidneys $(3.5 \mathrm{E}-02 \mathrm{mGy} / \mathrm{MBq})$.

The lesion-absorbed doses for the 2 visible lesions in patients 2 and 5 were calculated from the corresponding time-integrated activity coefficients with the OLINDA/EXM unit density sphere model.

The time-integrated activity coefficients for the 2 visible lesions (volume, $16 \mathrm{~mL}$ in patient 2 and $24 \mathrm{~mL}$ in patient 5) in patients 2 and 5 were $0.005 \pm 0.001$ and $0.003 \pm 0.001 \mathrm{~h}$, respectively. The time-integrated activity coefficients correspond to absorbed doses of $22 \mathrm{mGy}$ (patient 2) and $8 \mathrm{mGy}$ (patient 5) for an injection of $150 \mathrm{MBq}$.

The average effective doses calculated individually for each patient with the tissue-weighting factors from ICRP publication 60 were $1.58 \mathrm{E}-02 \pm 0.06 \mathrm{E}-02 \mathrm{mSv} / \mathrm{MBq}$. The SD of the effective dose was calculated by taking the mean of the individual patients' effective doses. The effective dose when the mean time-integrated activity coefficients were used resulted in a value of $1.56 \mathrm{E}-02 \mathrm{mSv} / \mathrm{MBq}$ (Table 3). Both values agree well. The effective dose for an injection of $150 \mathrm{MBq}$ of ${ }^{68} \mathrm{Ga}$-pentixafor is $2.3 \mathrm{mSv}$. The effective dose using ICRP 103 tissue-weighting factors for the standard patient is $1.46 \mathrm{E}-02 \mathrm{mSv} / \mathrm{MBq}$.

\section{DISCUSSION}

The human biodistribution and dosimetry of ${ }^{68} \mathrm{Ga}$-pentixafor were assessed in patients with multiple myeloma. The urinary bladder wall received the highest absorbed dose $(0.08 \mathrm{mGy} / \mathrm{MBq})$, followed by spleen and the kidneys. As a result of different individual filling states, the gallbladder exhibited the highest variability in the absorbed dose. ${ }^{68} \mathrm{Ga}$-pentixafor uptake was high in the lesions of 
TABLE 4

Comparison of Absorbed Dose Coefficients and Absorbed Doses for Several Compounds Labeled with ${ }^{68} \mathrm{Ga}$ and ${ }^{18} \mathrm{~F}-\mathrm{FDG}$

\begin{tabular}{|c|c|c|c|c|c|c|c|c|c|}
\hline $\begin{array}{l}\text { Target } \\
\text { organ }\end{array}$ & Units & $\begin{array}{c}\text { DOTATATE } \\
\text { (Walker } \\
(21))\end{array}$ & $\begin{array}{c}\text { DOTATOC } \\
\text { (Hartmann } \\
(19))\end{array}$ & $\begin{array}{c}\text { DOTANOC } \\
\text { (Pettinato } \\
(18))\end{array}$ & $\begin{array}{c}\text { DOTATOC } \\
\text { (Sandstrom } \\
(20))\end{array}$ & $\begin{array}{c}\text { DOTATATE } \\
\text { (Sandstrom } \\
(20))\end{array}$ & $\begin{array}{c}\text { HA-DOTATATE } \\
\text { (Hartmann } \\
(22))\end{array}$ & $\begin{array}{c}{ }^{18} \mathrm{~F}-\mathrm{FDG}(\mathrm{ICRP} \\
106(23))\end{array}$ & $\begin{array}{l}\text { Pentixafor } \\
\text { (this work) }\end{array}$ \\
\hline Kidneys & $\mathrm{mSv} / \mathrm{MBq}$ & $9.21 \mathrm{E}-02$ & 2.20E-01 & 8.97E-02 & 8.20E-02 & $9.30 \mathrm{E}-02$ & $1.55 \mathrm{E}-01$ & 1.70E-02 & 3.50E-02 \\
\hline Liver & $\mathrm{mSv} / \mathrm{MBq}$ & $4.50 \mathrm{E}-02$ & 7.40E-02 & 3.38E-02 & 4.10E-02 & $5.00 \mathrm{E}-02$ & $1.19 \mathrm{E}-01$ & $2.10 \mathrm{E}-02$ & 1.75E-02 \\
\hline Spleen & $\mathrm{mSv} / \mathrm{MBq}$ & $2.82 \mathrm{E}-01$ & 2.40E-01 & 7.25E-02 & $1.08 \mathrm{E}-01$ & $1.09 \mathrm{E}-01$ & $2.62 \mathrm{E}-01$ & 1.10E-02 & 5.38E-02 \\
\hline $\begin{array}{l}\text { Urinary } \\
\text { bladder } \\
\text { wall }\end{array}$ & $\mathrm{mSv} / \mathrm{MBq}$ & $1.25 \mathrm{E}-01$ & 7.00E-02 & 8.36E-02 & 1.19E-01 & $9.80 \mathrm{E}-02$ & 3.84E-02 & $1.30 \mathrm{E}-01$ & 8.14E-02 \\
\hline $\begin{array}{l}\text { Effective } \\
\text { dose } \\
\text { coefficient }\end{array}$ & $\mathrm{mSv} / \mathrm{MBq}$ & $2.57 \mathrm{E}-02$ & 2.30E-02 & 1.67E-02 & $2.10 \mathrm{E}-02$ & $2.10 \mathrm{E}-02$ & $2.45 \mathrm{E}-02$ & $1.90 \mathrm{E}-02$ & 1.56E-02 \\
\hline $\begin{array}{l}\text { Typical } \\
\text { injected } \\
\text { activity }\end{array}$ & $\mathrm{MBq}$ & 185 & 185 & 74 & 185 & 150 & 120 & 370 & 150 \\
\hline $\begin{array}{c}\text { Effective } \\
\text { dose }\end{array}$ & $\mathrm{mSv}$ & 4.8 & 4.3 & 1.2 & 3.9 & 3.2 & 2.9 & 7.0 & 2.3 \\
\hline
\end{tabular}

2 patients while having low background activity, suggesting that this new compound may be useful as a theranostic in a subgroup of patients (Fig. 1).

For the bone marrow dosimetry, the mean time-integrated activity coefficient was higher when the image-based method was used than the values obtained by the blood-based method, which is in agreement with the data by Ferrer et al. (10) obtained after radioimmunotherapy. Overall, the absorbed doses to the bone marrow in our group of patients were of the order of several $\mathrm{mGy}$ for an administered activity of $150 \mathrm{MBq}$.

Until 2013, only sparse data were available for the diagnostic use of ${ }^{68} \mathrm{Ga}$-labeled peptides (17). Pettinato et al. provided results for ${ }^{68} \mathrm{Ga}$-DOTANOC (18) and Hartmann et al. data for ${ }^{68} \mathrm{Ga}-$ DOTATOC (19). Only recently, Sandstrom et al. compared dosimetry data for ${ }^{68} \mathrm{Ga}$-DOTATOC and ${ }^{68} \mathrm{Ga}$-DOTATATE (20), and Walker et al. (21) and Hartmann et al. (22) published dosimetry data for ${ }^{68} \mathrm{Ga}$-DOTATATE (21) and ${ }^{68} \mathrm{Ga}$-HA-DOTATATE (22), respectively. Table 4 provides an overview on the absorbed doses for selected organs and the corresponding effective doses for our work and published data. In addition, the data for ${ }^{18} \mathrm{~F}-\mathrm{FDG}$ PET are given (data taken from ICRP 106 (23)). For ${ }^{68} \mathrm{Ga}$-pentixafor, the absorbed doses to the liver, kidney, and spleen are much lower than for the other ${ }^{68} \mathrm{Ga}$-labeled radiopharmaceuticals, resulting in a low effective dose of $2.3 \mathrm{mSv}$ after administration of $150 \mathrm{MBq}$ of ${ }^{68} \mathrm{Ga}$-pentixafor.

The urinary excretion does not rely on model assumptions. In fact, the current data were obtained after an observation period of at least $4 \mathrm{~h}$ after injection. At this time, $4 \%-8 \%$ of the injected activity was still retained in the whole body. A comparison of the time-integrated activity coefficients of the bladder contents to the activity in the remainder of the body shows that, as a conservative estimate, less than $10 \%$ of the injected activity was excreted through the urinary tract. Thus, the absorbed dose to the bladder wall from $150 \mathrm{MBq}$ of ${ }^{68} \mathrm{Ga}$-pentixafor is significantly lower than that from ${ }^{18} \mathrm{~F}$-FDG (16). Importantly, the tracer was well tolerated by all patients. No acute or subacute adverse events were observed, and no significant changes in total blood count, kidney, or hepatic function occurred.
Wester et al. (24) demonstrated in patients with lymphomas that ${ }^{68} \mathrm{Ga}$-pentixafor is a promising new probe for the in vivo mapping of CXCR4, with excellent pharmacokinetics and rapid excretion. Furthermore, Philipp-Abbrederis et al. (25) recently showed that ${ }^{68} \mathrm{Ga}$-pentixafor detects CXCR4 expression in multiple myeloma with a high sensitivity.

Because ${ }^{68} \mathrm{Ga}$-pentixafor assays CXCR4 expression in vivo it can serve as a predictive biomarker for CXCR4-targeted treatment, such as radionuclide- or toxin-labeled CXCR4 ligands. ${ }^{68} \mathrm{Ga}$-pentixaforpositive lesions were identified in 2 of the 5 current subjects, which is consistent with an incidence of $43 \%$ CXCR4 positivity of tumor lesions in multiple-myeloma patients (26).

${ }^{68} \mathrm{Ga}$-pentixafor PET is not primarily aimed at establishing another diagnostic PET biomarker. Rather, reliable and robust detection of CXCR4 expression is the prerequisite for its use as a CXCR4-directed theranostic. Thus, ${ }^{68} \mathrm{Ga}$-pentixafor could serve as predictive or enrichment biomarkers whereas the ${ }^{177} \mathrm{Lu}$ - or ${ }^{90} \mathrm{Y}-$ labeled analogs would provide the therapeutic arm. This concept has proven successful in the context of somatostatin receptor imaging and therapy. Given the important role of CXCR4 in various cancers, a rapidly expanding number of applications for ${ }^{68} \mathrm{Ga}-$ pentixafor can be anticipated.

\section{CONCLUSION}

${ }^{68} \mathrm{Ga}$-pentixafor exhibits a favorable dosimetry and is not associated with any toxicity. It shows favorable imaging characteristics, with high lesion-to-background uptake ratios $30 \mathrm{~min}$ after intravenous injection. The urinary bladder wall was the critical organ. Low tracer uptake in normal bone marrow may be of particular interest for future therapeutic applications. Organ-absorbed doses associated with ${ }^{68} \mathrm{Ga}$-pentixafor are lower than those of other PET radiopharmaceuticals.

\section{DISCLOSURE}

The costs of publication of this article were defrayed in part by the payment of page charges. Therefore, and solely to indicate this fact, this article is hereby marked "advertisement" in accordance 
with 18 USC section 1734. Saskia Kropf and Hans-Juergen Wester are CEOs of SCINTOMICS. No other potential conflict of interest relevant to this article was reported.

\section{ACKNOWLEDGMENTS}

We thank Simone Seifert, Simone Groß, Michael Schulze-Glück (members of the nuclear medicine PET team), and Inge Grelle for their support and assistance.

\section{REFERENCES}

1. Maecke HR, Reubi JC. Somatostatin receptors as targets for nuclear medicine imaging and radionuclide treatment. $J$ Nucl Med. 2011;52:841-844.

2. Domanska UM, Kruizinga RC, Nagengast WB, et al. A review on CXCR4/ CXCL12 axis in oncology: no place to hide. Eur J Cancer. 2013;49:219-230.

3. Uy GL, Rettig MP, Motabi IH, et al. A phase $1 / 2$ study of chemosensitization with the CXCR4 antagonist plerixafor in relapsed or refractory acute myeloid leukemia. Blood. 2012;119:3917-3924.

4. Demmer O, Gourni E, Schumacher U, Kessler H, Wester HJ. PET imaging of CXCR4 receptors in cancer by a new optimized ligand. ChemMedChem. 2011;6:1789-1791.

5. Gourni E, Demmer O, Schottelius M, et al. PET of CXCR4 expression by a ${ }^{68} \mathrm{Ga}-$ labeled highly specific targeted contrast agent. J Nucl Med. 2011;52:1803-1810.

6. Martin R, Juttler S, Muller M, Wester HJ. Cationic eluate pretreatment for automated synthesis of $\left[{ }^{68} \mathrm{Ga}\right] \mathrm{CPCR} 4.2$. Nucl Med Biol. 2014;41:84-89.

7. Boellaard R, Hristova I, Ettinger S, et al. Initial experience with the EANM accreditation procedure of FDG PET/CT devices [abstract]. Eur J Cancer. 2011;47(suppl 4):S8.

8. Lassmann M, Chiesa C, Flux G, Bardies M. EANM Dosimetry Committee guidance document: good practice of clinical dosimetry reporting. Eur J Nucl Med Mol Imaging. 2011;38:192-200.

9. Kletting P, Schimmel S, Kestler HA, et al. Molecular radiotherapy: the NUKFIT software for calculating the time-integrated activity coefficient. Med Phys. 2013;40:102504.

10. Ferrer L, Kraeber-Bodere F, Bodet-Milin C, et al. Three methods assessing red marrow dosimetry in lymphoma patients treated with radioimmunotherapy. Cancer. 2010;116:1093-1100.

11. Sgouros G. Bone marrow dosimetry for radioimmunotherapy: theoretical considerations. J Nucl Med. 1993;34:689-694.
12. Stabin MG, Sparks RB, Crowe E. OLINDA/EXM: the second-generation personal computer software for internal dose assessment in nuclear medicine. $\mathrm{J} \mathrm{Nucl}$ Med. 2005;46:1023-1027.

13. International Commission on Radiological Protection (ICRP). 1990 Recommendations of the International Commission on Radiological Protection. ICRP publication 60. New York, NY: Pergamon Press; 1991:21.

14. International Commission on Radiological Protection (ICRP). The 2007 Recommendations of the International Commission on Radiological Protection. ICRP publication 103. Philadelphia, PA: Elsevier Health; 2007:37.

15. International Commission on Radiological Protection (ICRP). ICRP publication 110: adult reference computational phantoms. Ann ICRP. 2009;30.

16. Eberlein U, Broer JH, Vandevoorde C, et al. Biokinetics and dosimetry of commonly used radiopharmaceuticals in diagnostic nuclear medicine: a review. Eur J Nucl Med Mol Imaging. 2011;38:2269-2281.

17. Eberlein U, Lassmann M. Dosimetry of [Ga-68]-labeled compounds. Appl Radiat Isot. 2013;76:70-74.

18. Pettinato C, Sarnelli A, Di Donna M, et al. ${ }^{68} \mathrm{Ga}$-DOTANOC: biodistribution and dosimetry in patients affected by neuroendocrine tumors. Eur J Nucl Med Mol Imaging. 2008;35:72-79.

19. Hartmann H, Zöphel K, Freudenberg R, et al. Radiation exposure of patients during ${ }^{68} \mathrm{Ga}-\mathrm{DOTATOC}$ PET/CT examinations. Nuklearmedizin. 2009;48:201-207.

20. Sandström M, Velikyan I, Garske-Roman U, et al. Comparative biodistribution and radiation dosimetry of ${ }^{68} \mathrm{Ga}$-DOTATOC and ${ }^{68} \mathrm{Ga}$-DOTATATE in patients with neuroendocrine tumors. J Nucl Med. 2013;54:1755-1759.

21. Walker RC, Smith GT, Liu E, Moore B, Clanton J, Stabin M. Measured human dosimetry of ${ }^{68} \mathrm{Ga}$-DOTATATE. J Nucl Med. 2013;54:855-860.

22. Hartmann H, Freudenberg R, Oehme L, et al. Dosimetric measurements of ${ }^{68}$ Ga-high affinity DOTATATE: twins in spirit-part III. Nuklearmedizin. $2014 ; 53$.

23. International Commission on Radiological Protection (ICRP). ICRP publication 106: radiation dose to patients from radiopharmaceuticals-addendum 3 to ICRP publication 53. Ann ICRP. 2008;38.

24. Wester H, Keller U, Beer AB, et al. $\left[{ }^{68} \mathrm{Ga}\right]$ CPCR4.2-PET for imaging of CXCR4-chemokine receptors opens a new and exciting field of clinical research. Paper presented at: Annual Congress of the European Association of Nuclear Medicine; October 19-23, 2013; Lyon France.

25. Philipp-Abbrederis K, Herrmann K, Knop S, et al. In vivo molecular imaging of chemokine receptor CXCR4 expression in patients with advanced multiple myeloma. EMBO Med Mol. In press.

26. Bao L, Lai Y, Liu Y, et al. CXCR4 is a good survival prognostic indicator in multiple myeloma patients. Leuk Res. 2013;37:1083-1088. 